\title{
Management of organ transplant recipients attending a high-throughput skin cancer surgery and surveillance clinic in Queensland
}

DOI:

10.1111/bjd.17001

\section{Document Version}

Accepted author manuscript

Link to publication record in Manchester Research Explorer

Citation for published version (APA):

Papier, K., Gordon, L. G., Khosrotehrani, K., Isbel, N., Campbell, S., Griffin, A., \& Green, A. C. (2018).

Management of organ transplant recipients attending a high-throughput skin cancer surgery and surveillance clinic in Queensland. The British journal of dermatology. https://doi.org/10.1111/bjd.17001

\section{Published in:}

The British journal of dermatology

\section{Citing this paper}

Please note that where the full-text provided on Manchester Research Explorer is the Author Accepted Manuscript or Proof version this may differ from the final Published version. If citing, it is advised that you check and use the publisher's definitive version.

\section{General rights}

Copyright and moral rights for the publications made accessible in the Research Explorer are retained by the authors and/or other copyright owners and it is a condition of accessing publications that users recognise and abide by the legal requirements associated with these rights.

\section{Takedown policy}

If you believe that this document breaches copyright please refer to the University of Manchester's Takedown Procedures [http://man.ac.uk/04Y6Bo] or contact uml.scholarlycommunications@manchester.ac.uk providing relevant details, so we can investigate your claim.

\section{OPEN ACCESS}


DR KEREN PAPIER (Orcid ID : 0000-0002-4102-6835)

DR KIARASH KHOSROTEHRANI (Orcid ID : 0000-0002-6406-4076)

Article type : Original Article

\section{Management of organ transplant recipients attending a high-throughput skin cancer surgery and surveillance clinic in Queensland}

K. Papier ${ }^{1}$, L.G. Gordon ${ }^{1,2,3}$, K. Khosrotehrani ${ }^{4,5}$, N. Isbel ${ }^{6}$, S. Campbell ${ }^{6}$, A. Griffin ${ }^{6}$, A.C. Green ${ }^{1,7}$

${ }^{1}$ QIMR Berghofer Medical Research Institute, Population Health Department, Brisbane, Queensland, Australia

${ }^{2}$ Queensland University of Technology, School of Nursing, Institute of Health and Biomedical Innovation, Brisbane, Queensland, Australia

${ }^{3}$ The University of Queensland, School of Population Health, Brisbane, Queensland, Australia

${ }^{4}$ The University of Queensland, Centre for Clinical Research, Brisbane, Queensland, Australia

${ }^{5}$ The University of Queensland, Diamantina Institute, Translational Research Institute, Woolloongabba, Queensland, Australia

${ }^{6}$ Department of Nephrology, Princess Alexandra Hospital, Brisbane, Queensland, Australia

${ }^{7}$ CRUK Manchester Institute and Faculty of Biology Medicine and Health, University of Manchester, Manchester Academic Health Science Centre, Manchester, UK

Corresponding author: Keren Papier

Email: Keren.Papier@ndph.ox.ac.uk

Funding The work was supported by an Enabling Grant from the Australian Skin and Skin Cancer Research Centre. The funder had no involvement in the study design, data collection, data analysis, manuscript preparation, and/or publication decisions.

This article has been accepted for publication and undergone full peer review but has not been through the copyediting, typesetting, pagination and proofreading process, which may lead to differences between this version and the Version of Record. Please cite this article as doi: $10.1111 /$ bjd.17001

This article is protected by copyright. All rights reserved. 
Disclosure None declared.

Running head: Management of organ transplant recipients in a dermatologic surgical clinic.

\section{What is already known about this topic?}

- Organ transplant recipients (OTRs) have a greatly increased risk of skin cancer.

- Evidence suggests that specialized clinics dedicated to regular skin surveillance of OTRs may facilitate management of very high disease burdens in OTRs.

\section{What does this study add?}

- This is the first report of the performance of a dedicated high-throughput Transplant Skin Cancer Clinic in Australia.

- The skin cancer burden in OTRs living in regions with high background incidence can be successfully managed by dedicated outpatient dermatologic surgical clinics.

\section{Summary}

Background The incidence of skin cancer in organ transplant recipients (OTRs) is very high due mainly to long-term immunosuppressive therapy. The problem is particularly severe for organ transplant recipients living in Queensland, Australia, resulting in significant mortality.

Objective To describe the experience of the first dedicated outpatient high-throughput Transplant Skin Clinic in Queensland.

Methods This prospective evaluation study was conducted at a newly established, outpatient transplant skin cancer surgery and surveillance clinic. Participants (89 OTRs and 12 non- 
OTRs) were referred to the Princess Alexandra Hospital Transplant Skin Clinic, December 2016-May 2017, and were each followed for three months. Self-completed questionnaires were administered out-patient at baseline and end of follow-up ( $n=94)$ and details of any skin cancers occurring out-patient in that period were extracted from hospital records.

Results A total of 615 skin lesions were detected in the three-month follow-up of 101 OTRs, of which $478(78 \%)$ were treated in the Clinic, and $55(9 \%)$ were referred to another specialist. Of the 478 treated lesions, 268 were histopathologically confirmed skin cancers, equivalent to 2.7 (95\% confidence interval $2.5,2.8$ ) skin cancers per participant per three months .The overall number needed to treat for any skin cancer was $1.4,95 \% \mathrm{CI}(1.3,1.5)$. Three-quarters (374) of in-Clinic treatments were surgical, and most (90\%) were complete excisions. Median time from detection of skin cancer to excision was 7 days.

Conclusions This high-volume surgical outpatient Transplant Skin Clinic enables efficient treatment of skin cancers in very-high-risk OTRs.

\section{Introduction}

Organ transplant recipients (OTRs) have a greatly increased risk of skin cancer ${ }^{1}$, with the overall incidence of squamous cell carcinoma (SCC) and basal cell carcinoma (BCC) in OTRs some 30 times higher than in the general population ${ }^{2}$. The high risks of these keratinocyte cancers and of melanoma ${ }^{3}$ in OTRs are caused by the combined effects of solar ultraviolet radiation and immunosuppressive treatment ${ }^{1,4,5}$. Skin cancer morbidity and mortality in OTRs rise steeply with age, age at transplantation and duration of immunosuppression ${ }^{6,7}$. With greater potency of modern immunosuppressive drugs ${ }^{8}$ and 
improvements in graft survival ${ }^{9}$ fair-skinned OTRs around the world are surviving longer and the incidence of skin malignancies will only continue to increase.

Specialist clinics dedicated to regular skin surveillance of OTRs are vital for early treatment and control of skin cancers ${ }^{10,11}$. Such a service is especially needed in Queensland, Australia, with its high background skin cancer rates in the general population reaching beyond 2000/100,000 annual incidence ${ }^{12}$. More specifically, we have previously reported that $11 \%$ of OTRs in Queensland are affected by SCC in at any given point, clearly demonstrating the burden to be expected in such target population ${ }^{13}$. Traditional pathways of clinical diagnosis, biopsy and referral for therapy are ineffective in managing such high risk population and result in delays in treatment. To better control the extreme skin cancer problem in local OTRs, a Transplant Skin Clinic was thus established in Brisbane for dedicated outpatient management of skin cancer in very-high-risk OTRs. The specific aims of this study were to evaluate the work load of the Clinic and patient outcomes by documenting the frequency and outcomes of skin examinations and skin cancer treatments among attendees, and we also assessed attendee OTRs' satisfaction.

\section{Materials and methods}

\section{Study population and setting}

This study was conducted at the newly-established outpatient Transplant Skin Clinic at the Princess Alexandra Hospital which was implemented in March 2016 to expedite skin cancer treatment and provide health education to high-risk OTRs. The Clinic staff comprises three teams: 1) a dermatology team of one consultant and multiple registrars; 2) a surgical team, consisting of a senior surgeon (who determines the optimal excision modalities), a 
group of surgical registrars, and residents participating in procedures; and 3) a transplant team, many of whom cross-participate in the surgical team. Plastic surgeons, radiation oncologists, kidney and liver physicians are on call. The Clinic operates one afternoon each week and additional complex surgeries may be booked on other days of the week. The staff sees an average of eight patients per Clinic session (Fig 1).

All OTRs, and some with organ failure, lymphoproliferative diseases and/ or receiving immunosuppressive treatment, attending the Clinic from December 2016 to May 2017, were eligible to take part. Clinic attendees were those referred by nephrologists, transplant physicians, dermatologists from the Princess Alexandra Hospital, and/or through self-referral. Patient referral to the Clinic was based on skin cancer risk assessed as very high, history of skin cancer, and presence of severe photo damage. Patients were excluded if they were unable to give fully informed consent. Study procedures were approved by the QIMR Berghofer Human Research Ethics Committee (P2257) and the Metro South Human Research Ethics Committee (HREC/16/QPAH/703).

\section{Clinical management}

OTR patients were systematically reviewed in the clinic by dermatologists on a threemonthly basis. Suspicious lesions were fully excised with appropriate margins based on suspected diagnosis. This allowed a reduction in the common delay between clinical diagnosis, to biopsy, to excision that often results in the increased burden of the disease.

Excision surgery was performed by transplant or plastic surgeons immediately in the outpatient setting or in the coming week in surgical theatre for more complex intervention. Patients were also offered preventive therapy and advice and a review was organized in the next three months. 


\section{Data Collection}

At baseline, participants completed a self-administered questionnaire covering personal and socio-demographic characteristics (age, sex, employment status, education level, country of birth, ancestry), skin phototype and sun exposure habits, and medical histories. Each OTR was followed-up for three months and during that period, details of frequency of Clinic visits, skin examinations, and treatments or referrals to other clinical specialties were recorded. After the three months we re-administered the questionnaires to ascertain changes to transplant medications, subsequent visits to the Transplant Skin Clinic, and satisfaction with the Clinic. Participant satisfaction with the Clinic was assessed by five questions. The first asked participants to rate the Clinic for meeting patient needs using a five-point Likert scale ranging from 'poor' to 'excellent'. The other four questions assessed the performance of the Clinic and the aspects that participants liked or disliked, again using a five-point Likert scale ranging from 'not at all' to 'very much'.

Histopathology reports of all suspicious lesions clinically diagnosed and either treated or referred were collected for the three-months of follow-up of each OTR in the study and biopsy methods and dates of diagnosis of single or multiple cancers were extracted to assess the surgical burden and skin cancer outcomes. Date(s) of transplantation(s) and immunosuppressive therapy regimens were obtained from medical records.

\section{Data analysis}

All data were cleaned and checked for errors against the original surveys and medical records. Baseline characteristics, clinic treatments and procedures, histopathological diagnoses, and OTR referral for management of skin lesions over the three-month follow up 
were summarized for all participants. We calculated the number of skin cancers per participant; the denominator included the total person-time contributed by each participant and the numerator included all histopathologically confirmed skin cancers during the threemonth follow-up. We also calculated the number needed to treat (NNT) by dividing the total number of biopsied or excised lesions by the total number of histopathologically confirmed skin cancers.

\section{Results}

Of 111 OTRs attending the Transplant Skin Clinic and invited to participate, 101 (91\%) agreed and of these $94(93 \%)$ completed the follow-up questionnaire. Those who declined to take part were predominantly men $(91 \%)$ of average age 55years.

Of the 101 participants at baseline (average age 63y; $77 \%$ men; $78 \%$ of British or Irish descent), 89 were OTRs (79 kidney and 8 liver, representing around 10\% of kidney transplant and $1 \%$ of liver transplant recipients followed-up at the Princess Alexandra Hospital, 1 lung, 1 heart, transplanted on average 14 years previously) and 12 were awaiting transplantation and/or had a history of many skin cancers. Those awaiting transplants represented around 5\% of patients awaiting kidney transplantation annually, and although only 2 were using immunosuppressive medication, they were similar in socio-demographic characteristics to the 89 OTRs. Half (49\%) were on triple immunosuppressive therapy. Over half $(56 \%)$ of participants did not complete high school and $41 \%$ were considered low income (Table 1). Nearly half $(49,48 \%)$ reported a tendency to burn on acute sun exposure, about one quarter $(27,27 \%)$ reported having mostly outdoor occupations in life, and 42 $(42 \%)$ reported mainly outdoor recreational activities. 
During their three-month follow up periods, the 101 study participants attended the Clinic on a total of 224 occasions, with a median attendance (first, third quartiles) of $2(1,3)$ per OTR. During their cumulated follow-up, Clinic staff performed 141 full skin examinations and detected 615 suspicious skin lesions of which $478(78 \%)$ were managed by surgical and/or other modality by the team. The majority $(374,74 \%)$ of in-Clinic procedures were surgical (337 complete excisions, 32 shave excisions, 5 punch biopsies,) (Table 2), performed either under local anaesthesia or in the operating room under general anaesthesia. The median time (first, third quartiles) between lesion detection and definitive surgical treatment was 7 days $(0,31)$, with over one third (152) of lesions undergoing therapeutic excision on the day of detection. A median of 2 lesions (first, third quartiles: 1, 4) were excised per patient per visit with the highest number being 24 excised in a single visit.

Fifty-five (9\%) of the lesions detected in the Clinic (from 17 participants) were referred to another specialist (plastic surgeon (24), surgeon (16), radiotherapy (7), dermatologist (3), mostly (34, 62\% within the Hospital) or a general practitioner (5). Of the 55 lesions, 51 lesions were referred without treatment and 4 lesions were referred after destructive treatment. The majority of referrals were for complex cases (i.e. plastic surgery) or for ongoing treatment. Over their three-month follow-up, 12 participants (13\%) reported that their transplant medication had been altered solely because of their skin cancers. This change was the result of direct communication that took place between Clinic staff and transplant physicians.

In total, 101 participants had 268 histopathologically confirmed skin cancers (93 SCCs, 114 Bowen's disease, 22 keratoacanthoma, 38 BCCs, 1 melanoma in situ,) during their follow-up (Table 3), equivalent to $2.7,95 \%$ Confidence Interval (CI) $(2.5,2.8)$ skin cancers per participant per three months. These 268 cancers were diagnosed from a total of 374 suspicious skin lesions that were biopsied or excised, yielding a NNT of 1.4, 95\% CI (1.3, 
1.5) for any skin cancer. Of the confirmed SCCs, 35 (42\%) were well differentiated, 44 $(52 \%)$ were moderately differentiated, and $5(6 \%)$ were poorly differentiated; 4 (4\%) SCCs were greater than $2 \mathrm{~cm}$ in diameter and $8(10 \%)$ had invaded beyond the dermis. The majority of the excised BCCs were solid or nodular $(24,65 \%)$. Sites most affected were upper limbs with $106(40 \%)$ and head and neck with $84(31 \%)$; the remainder were on lower limbs, 57 (21\%); chest, $12(5 \%)$; and back, $9(3 \%)$.

The majority of OTR study participants $(88 \%)$ rated the Transplant Skin Clinic as 'very good' or 'excellent' for attending to their needs and nearly all (95\%) reported that they were very satisfied with the performance of the Clinic. Most $(79,85 \%)$ agreed strongly that they liked attending because they received all of their skin cancer treatment in one clinic, 70 (76\%) agreed strongly that it saved them worrying about their skin cancers while they waited for surgery, and $63(77 \%)$ felt they received superior care for their skin cancers at the Transplant Skin Clinic.

\section{Discussion}

This is the first report of the performance of a dedicated high-throughput Transplant Skin Cancer Clinic in Australia. Our results indicate that such a Clinic meets a high demand by detecting and treating numerous skin cancers in high-risk OTRs as well as managing the referral of many complex skin cancers. The Clinic's achievement of such a high-volume of surgical treatments can be attributed to its highly-experienced and multidisciplinary specialist staff ${ }^{10,11,14,15}$. Also as a result of the tertiary hospital setting, Clinic staff can communicate and consult regularly with other specialists across various hospital departments and with a large number of community health-care practitioners, often at point of care (with patients generally seen within two weeks of referral). This coordination of care enables Clinic staff to 
triage OTRs presenting with skin cancers efficiently within less than 7 days in median and provide full skin surveillance three monthly fulfilling the aim of appropriate treatment in a time-effective manner.

Three-quarters of all in-Clinic treatments provided were surgical, of which $90 \%$ were complete excisions and in keeping with previous studies, there were substantially more SCCs treated than BCCs ${ }^{14,16,17}$. As expected, the observed rate of skin cancer excisions performed in this Clinic surpassed that of non-specialized skin cancer surveillance clinics ${ }^{18-20}$, highlighting the fact that OTRs have an increasingly high risk of recurring and aggressive skin cancers compared with the general population and thus complete and early excision of skin cancers in this vulnerable group is critical ${ }^{1}$. A noteworthy finding was that the number of lesions excised per patient visit was high, with numbers reaching up to 24 in one patient visit. This high-volume treatment will likely lead to far fewer outpatient visits by the OTRs, reduce their out-of-pocket costs, and bring cost savings for the Princess Alexandra Hospital. Further research is required to quantify these potential savings.

The NNT for any skin cancer was 1.4 (i.e. 1.4 skin lesions were excised or biopsied to identify 1 skin cancer). Although direct comparisons are difficult due to differences in case ascertainment, inclusion criteria, and sampling, our estimate was lower than those reported by previous studies that included keratinocyte skin cancers in their estimates ${ }^{21,22}$. We had expected that this Clinic would perform well because it is specialist-led, dedicated to surgery and surveillance in high-risk, highly selected OTRs. The main cause for misdiagnosis was solar keratoses, that can be hypertrophic and therefore mimic Bowen's or SCC lesions. Our data demonstrate that skin cancers are effectively identified and efficiently managed by treating a high volume of skin cancers without the use of unnecessary biopsy. 
Attending OTRs reported being very satisfied with the Clinic's performance. In particular, OTRs appreciated receiving all of their skin cancer treatment in the one Clinic and reported it saved them from worrying about their skin cancers while awaiting definitive surgery. Prior to establishment of this Clinic, OTRs typically attended multiple departments within the Princess Alexandra Hospital on multiple occasions to have their skin examined, suspicious lesions biopsied, and suspected skin cancers excised. Previous clinical pathways also included multiple referrals: from transplantation physicians to dermatologists, where multiple visits were required for diagnosis, biopsy and finally for definitive treatment or referral to surgeons. With the advent of the Transplant Skin Clinic, OTRs now could have routine (approximately three-monthly) skin examinations and receive all of their skin cancer treatment at once. In summary this 'one-stop shop' reduced patient waiting times and facilitated early skin cancer treatment.

While the generalizability of our findings may be limited by our sample size and limited follow-up period, our participants were very similar to those from the much larger Skin Tumours in Allograft Recipients (STAR) study who represented the majority of highrisk OTRs attending the Princess Alexandra Hospital ${ }^{13}$. Important strengths of this study included the use of medical charts to confirm personal and medical data and the nine-months of cumulated data collection which eliminated effects of seasonality.

\section{Conclusions}

With improvements in transplantation techniques, the burden of skin cancers in aging OTRs will continue to grow unless effective surveillance and treatment measures are put in place. Our findings indicate that specialist outpatient skin cancer clinics for OTRs such as the Princess Alexandra Hospital's Transplant Skin Clinic described here, provide timely skin 
surveillance and prompt, high-volume treatment of skin cancers and thereby make significant contributions to controlling the skin cancer burden in OTRs.

\section{References}

1 Euvrard S, Kanitakis J, Claudy A. Skin cancers after organ transplantation. The New England journal of medicine 2003; 348: 1681-91.

2 Grulich AE, van Leeuwen MT, Falster MO et al. Incidence of cancers in people with HIV/AIDS compared with immunosuppressed transplant recipients: a meta-analysis. Lancet (London, England) 2007; 370: 59-67.

3 Green AC, Olsen CM. Increased risk of melanoma in organ transplant recipients: systematic review and meta-analysis of cohort studies. Acta dermato-venereologica 2015; 95: 923-7.

4 Bouwes Bavinck JN, Hardie DR, Green A et al. The risk of skin cancer in renal transplant recipients in Queensland, Australia. A follow-up study. Transplantation 1996; 61: 715-21.

5 Mudigonda T, Levender MM, O'Neill JL et al. Incidence, risk factors, and preventative management of skin cancers in organ transplant recipients: a review of single- and multicenter retrospective studies from 2006 to 2010. Dermatologic surgery : official publication for American Society for Dermatologic Surgery [et al.] 2013; 39: 345-64.

6 Bouwes Bavinck JN, Euvrard S, Naldi L et al. Keratotic skin lesions and other risk factors are associated with skin cancer in organ-transplant recipients: a case-control study in The Netherlands, United Kingdom, Germany, France, and Italy. The Journal of investigative dermatology 2007; 127: 1647-56.

7 Ulrich C, Schmook T, Sachse MM et al. Comparative epidemiology and pathogenic factors for nonmelanoma skin cancer in organ transplant patients. Dermatologic surgery : official publication for American Society for Dermatologic Surgery [et al.] 2004; 30: 622-7.

8 Luppi M, Barozzi P, Torelli G. Skin cancers after organ transplantation. The New England journal of medicine 2003; 349: 612-4; author reply -4.

9 Sam R, Leehey DJ. Improved graft survival after renal transplantation in the United States, 1988 to 1996. The New England journal of medicine 2000; 342: 1837-8.

10 Christenson LJ, Geusau A, Ferrandiz C et al. Specialty clinics for the dermatologic care of solid-organ transplant recipients. Dermatologic surgery : official publication for American Society for Dermatologic Surgery [et al.] 2004; 30: 598-603.

11 Zwald FO, Brown M. Skin cancer in solid organ transplant recipients: advances in therapy and management: part II. Management of skin cancer in solid organ transplant recipients. Journal of the American Academy of Dermatology 2011; 65: 263-79; quiz 80.

12 Perera E, Gnaneswaran N, Staines C et al. Incidence and prevalence of nonmelanoma skin cancer in Australia: A systematic review. The Australasian journal of dermatology 2015; 56: 258-67.

This article is protected by copyright. All rights reserved. 
13 Iannacone MR, Sinnya S, Pandeya N et al. Prevalence of Skin Cancer and Related Skin Tumors in High-Risk Kidney and Liver Transplant Recipients in Queensland, Australia. The Journal of investigative dermatology 2016; 136: 1382-6.

14 Maurice PD, Fenton T, Cross N et al. A dedicated dermatology clinic for renal transplant recipients: first 5 years of a New Zealand experience. The New Zealand medical journal 2013; 126: 27-33.

15 Otley CC. Organization of a specialty clinic to optimize the care of organ transplant recipients at risk for skin cancer. Dermatologic surgery : official publication for American Society for Dermatologic Surgery [et al.] 2000; 26: 709-12.

16 Mackenzie KA, Wells JE, Lynn KL et al. First and subsequent nonmelanoma skin cancers: incidence and predictors in a population of New Zealand renal transplant recipients. Nephrology, dialysis, transplantation : official publication of the European Dialysis and Transplant Association - European Renal Association 2010; 25: 300-6.

17 Traywick C, O'Reilly FM. Management of skin cancer in solid organ transplant recipients. Dermatologic therapy 2005; 18: 12-8.

18 Askew DA, Wilkinson D, Schluter PJ et al. Skin cancer surgery in Australia 20012005: the changing role of the general practitioner. The Medical journal of Australia 2007; 187: 210-4.

19 Wilkinson D, Askew DA, Dixon A. Skin cancer clinics in Australia: workload profile and performance indicators from an analysis of billing data. The Medical journal of Australia 2006; 184: 162-4.

20 Byrnes P, Ackermann E, Williams ID et al. Management of skin cancer in Australia-a comparison of general practice and skin cancer clinics. Australian family physician 2007; 36: 1073-5.

21 Baade PD, Youl PH, Janda M et al. Factors associated with the number of lesions excised for each skin cancer: a study of primary care physicians in Queensland, Australia. Arch Dermatol 2008; 144: 1468-76.

22 FitzGerald KL, Buttner PG, Donovan SA. Nonpigmented skin lesions - how many are nonmelanoma skin cancer? Australian family physician 2006; 35: 555-7.

This article is protected by copyright. All rights reserved. 
Table 1. Characteristics of 101 patients attending the Transplant Skin Clinic

\section{Characteristics $^{\mathrm{a}}$}

n (\%)

Age in years

Overall, mean (SD)

$63(10)$

$<40$

$40-49$

$50-59$

60-69

$39(38)$

$70+$

$21(21)$

Sex

Men

Women

Born in Australia

Yes

Highest level of attained education

left school $<15$ or no school

completed grade 10

completed grade 12

completed a trade/technical certificate or diploma

completed university/college degree

Annual household income (AUD)

This article is protected by copyright. All rights reserved. 
$<30,000$

$30,000-79,999$

80,000 or more

$20(22)$

Reaction to 30 minutes of sun (first day of summer)

not burn

burn a little

$34(34)$

burn moderately

$30(29)$

burn badly

$19(19)$

Main occupation type since leaving school

mainly indoors

$44(44)$

both indoors and outdoors

$28(28)$

mainly outdoors

$27(27)$

Main recreation type since leaving school

mainly indoors

both indoors and outdoors

$31(31)$

mainly outdoors

$42(42)$

Time (years) since first transplant ${ }^{\mathrm{b}}$

Overall, mean (SD)

$14(12)$

$1-5$

$22(25)$

$>5-10$

$16(18)$

$>10-20$

$30(34)$

This article is protected by copyright. All rights reserved. 
Immunosuppressive therapy regimens at baseline

Antimetabolites ${ }^{\mathrm{c}}$

Antimetabolites and Calcineurin inhibitors

Antimetabolites and Corticosteroid

Calcineurin inhibitors ${ }^{\mathrm{d}}$

Corticosteroid $^{\mathrm{e}}$

Calcineurin inhibitors and Corticosteroid

Triple therapy ${ }^{\mathrm{f}}$

49 (49)

mTOR inhibitors ${ }^{\mathrm{g}}$

$7(7)$

Results are expressed as numbers with percentages in parentheses unless otherwise stated.

${ }^{a}$ Numbers may not add to total sample size due to missing responses for some characteristics.

${ }^{\mathrm{b}}$ Calculated based on the length of time between the date of first transplantation and date at participants' baseline survey

${ }^{c}$ Mycophenolate or Azathioprine

${ }^{\mathrm{d}}$ Tacrolimus or Cyclosporin

${ }^{\mathrm{e}}$ Prednisolone

${ }^{\mathrm{f}}$ Antimetabolites and Calcineurin inhibitors and Corticosteroid

${ }^{\mathrm{g}}$ Everolimus or Sirolimus

This article is protected by copyright. All rights reserved. 
Table 2. Treatments and procedures among 101 Clinic participants each followed for three months

Total number $(\mathrm{n}=\mathbf{5 0 3})$

Lesions treated, $\mathrm{n}(\%)$ $478(100)$

Non-surgical treatment provided, $n(\%)$

$129(26)$

Types of non-surgical treatment given, $\mathrm{n}(\%)$

Destructive treatment

Systemic chemoprevention $10(8)$

Surgeries performed, $n(\%)$

Types of surgeries performed, n (\%)

Complete

Shave excision

Punch biopsy

Results are expressed as numbers with percentages in parentheses.

This article is protected by copyright. All rights reserved. 
Table 3. Histopathological diagnoses among 101 participants over three months

Lesion types

n $(\%)$

Skin cancers detected

$268(100)$

Squamous cell carcinoma

$93(35)$

Tumor diameter, $\mathrm{cm}$

$<2$

$>2$

Tumor differentiation

Poorly differentiated

Moderately differentiated

Well differentiated

Tumor depth

Dermis

Fat

Bowen's disease (IEC)

$114(42)$

Keratoacanthoma

$22(8)$

Basal cell carcinoma

38 (14)

Sub-type

Solid or nodular

Superficial

$11(29)$

nodulo-ulcerative

Infiltrative

This article is protected by copyright. All rights reserved. 
Other lesions detected

Types of other lesions detected

Solar keratosis

Seborrhoeic keratosis

Nevus

Other benign lesions

Results are expressed as numbers with percentages in parentheses.

This article is protected by copyright. All rights reserved. 
Figure 1. Pre and post-Transplant Skin Clinic care and referral pathway

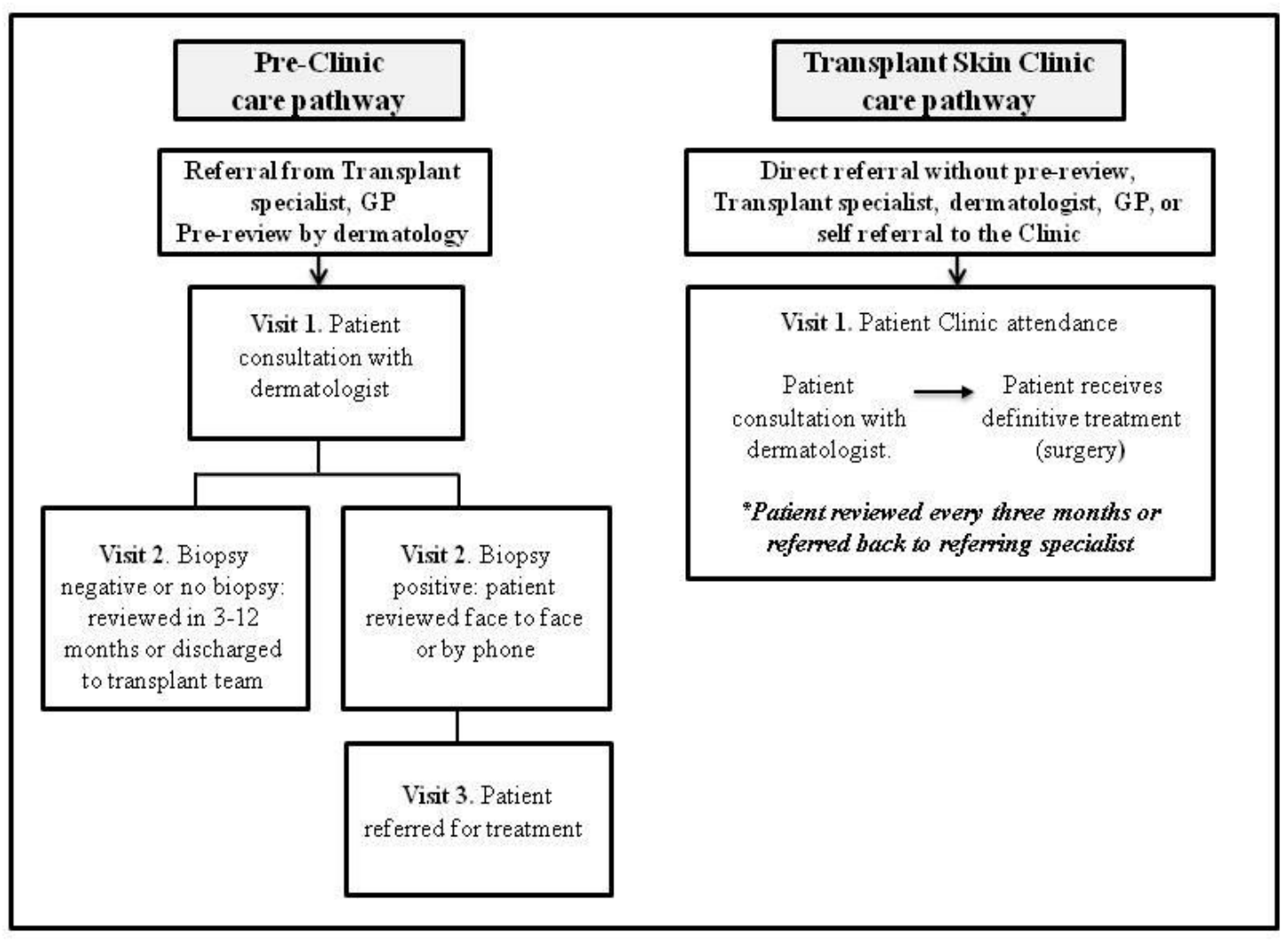

This article is protected by copyright. All rights reserved. 